\title{
Gender and the Labour Market in Ghana: The Relationship in Terms of the Family, the Market and the State
}

\author{
Ridwan Abukari' ${ }^{1}$, Ransford Okoe Odai ${ }^{2}$ \\ ${ }^{1}$ International Institute of Social Studies, Erasmus University Rotterdam, Rotterdam, The Netherlands \\ ${ }^{2}$ School of Political Science and Public Administration, University of Electronic Science and Technology of China, Chengdu, China \\ Email: niiokoe@hotmail.co.uk
}

How to cite this paper: Abukari, R., \& Odai, R. O. (2018). Gender and the Labour Market in Ghana: The Relationship in Terms of the Family, the Market and the State. Advances in Applied Sociology, 8, 285-294.

https://doi.org/10.4236/aasoci.2018.84015

Received: February 17, 2018

Accepted: April 9, 2018

Published: April 12, 2018

Copyright $\odot 2018$ by authors and Scientific Research Publishing Inc. This work is licensed under the Creative Commons Attribution International License (CC BY 4.0).

http://creativecommons.org/licenses/by/4.0/

(c) (i) Open Access

\begin{abstract}
The phenomenon of sex-segregation in the labour market continues to exist in a growing economy such as Ghana. The sex-based traditional occupational system of the economic sector is deeply rooted in the beliefs systems of the people. And so, the gender division of labour continues to define gender relationship among people in the society. Consequently, gender division of labour finds meaning and interpretation within the labour market in Ghana. However, for some reasons, people do overcome this occupational segregation by engaging in jobs that are by custom not meant for their sexuality. This statement reveals an inherent assumption about gender and the labour market; which needs further reflection and critical analysis. This paper focuses on gender and the labour market in Kumasi (a commercial town in Ghana); focusing on the gender identities, ideologies as well as symbols that affect the whole gamut of the labour market as a gendered institution in Ghana. Similarly, how the labour market interacts in the context of the family and the state respectively, will also be given a fair attention. The argument is categorised into ten steps: first; introduction of the subject matter, second; the region of Kumasi; the unit of analysis, third; methodology, fourth; an overview of the labour market in Ghana, fifth; the mode of entering/gaining access into food vending industry by men, sixth; challenges men face in the food vending industry in Kumasi, seventh; gender in food vending business verses socio-cultural practices, eighth; gender-labour market nexus; implication on the family and the state and finally, what the State, civil society organisations as well as the individuals or groups, need to do to improve this sector are recommended.
\end{abstract}

\section{Keywords}

Kumasi, Ghana, Food Vending, Gender, Division of Labour, Labour Market 


\section{Introduction}

The phenomenon of sex-segregation in the labour market continues to exist in a growing economy such as Ghana. Forkuor (2016: p. 94) argues that the sex-based traditional occupations in the sector of the economy in many parts of Africa are deeply rooted in the beliefs systems of the people. Therefore, the gender division of labour, in terms of task allocation to some people continues to define gender relationship among people in the society. Also, gender division of labour finds interpretation within the labour market in Africa. For instance, in Ghana, trading in vegetables, cooking utensils and other household items as well as food vending are traditionally meant for women. On the other hand, people will expect men in business to engage in jobs such as banking, engineering, yam business, law and the like. "Nonetheless, some men and women do overcome the occupational segregation by working in occupations that are not traditional to their sex" (Forkuor, 2016: p. 94). They do so by either using it as an economic survival strategy or by choice Aggleton et al. (2016). This statement reveals an inherent assumption about gender and the labour market that certain jobs (the less/unskilled) are meant for women and the highly skilled ones are for men. This perception needs further reflection and critical analysis.

This discussion centres on gender and the labour market in Kumasi (a commercial town in Ghana); focusing on the gender identities, ideologies as well as symbols that affect the whole gamut of the labour market as a gendered institution in Ghana. Similarly, how the labour market interacts within the context of the family and the state will also be given a fair attention. The argument is categorised into ten steps: first; introduction of the subject matter, second; the region of Kumasi; the unit of analysis, third; methodology, fourth; an overview of the labour market in Ghana, fifth; the mode of entering/gaining access into food vending industry by men, sixth; challenges men face in the food vending industry in Kumasi, seventh; gender in food vending business verses socio-cultural practices, eighth; gender-labour market nexus; implication on the family and the state and also what the state, civil society organisations as well as the individuals or groups, need to do to improve this sector are recommended and finally, the way forward. This structure gives the reader a broader perspective for in-depth reflection and critical analysis on the labour market as a gendered institution and how its conventional practices resonate with other gendered institution such as the family and the state.

\section{The Region of Kumasi: The Unit of Analysis}

Kumasi is a multi-cultural society with different religious beliefs and practices. Even though Christianity is the predominant religion practiced by most people, the traditional beliefs system is still invoked to give interpretation to certain social practices. In terms of formal education, the illiteracy rate (35.0\%) is relatively high and that people are driven and interpret issues based on their inherent cultural inclinations (Asenso-Okyere, Twum-Baah, Kasanga, Anum, \& Pörtner, 
2000). What makes Kumasi unique is its commercialised status that attracts many from other regions of the country to engage in all forms of businesses. Consequently, Kumasi was chosen because this will help me to launch my analysis on the subject matter of the discourse.

\section{Methodology}

This paper is a critical reflection on theorization of gendered institutions where closed attentions are paid on the impact of collective and individual actions and interventions in the fields of economic exclusion, sexuality and culture, from an intersectional perspective. This paper reviews some of the diverse relevant literature that touches gender and the labour market, with specific focus on gender identities, ideologies, and symbols that affect the whole scope of the labour market as a gendered institution. The strategy in the paper is to consider the evidence, data, issues and analysis in the literature covering gender and the labour market. There is a wide range of differences both in men and women's trade with its implication on the family across Ghana. Similarly, there is a slight range of differences considering the working environment of both males and females in the labour market. In reviewing the literature, attention is paid to locate the mode of how men gain access into trade and also considered gender in food vending business against some cultural practices. Both empirical and theoretical research touching these issues has been done in several areas of economics such as labour economics, family economics and studies on growth. In this regard, this paper demonstrates intersectionality in relation to the gendered institutions: family, market and the state in terms of sexuality, occupation and culture in the context of the food vending industry in the commercial city of Kumasi in Ghana as a case study.

\section{An Overview of the Ghanaian Economy; the Composition of the Labour Market}

The sector of the economy of Ghana is basically made up of both formal (service providing entities-both public and private) and informal (nonskilled labour) sector. The formal sector provides most of the managerial services; banking and finance, transport and communication services and the bureaucratic managerial services. The informal sector which employs the majority of the population include the subsistence agriculture, migrants work services, traditional trade; blacksmith work, butchering (the art of selling meat), petty trading and food vending among others. Haug (2014: p. 1), finds out that about $90.9 \%$ work force in Ghana represent women in the informal sector of the economy. Most often than not, many of them work in the informal way of catering by engaging in food vending business for their livelihood.

Ghana has a dual labour market split between a pre-industrialised agricultural sector and a modern sector. The sector also has a slightly higher employment of men than women, which is unusual for the agricultural sector in Sub-Saharan 
Africa. Females find employment in several other sectors, but predominantly in trade, restaurants and hotels as well as manufacturing (Ghana Statistical Service, 2013). By law, the maximum working week is 45 hours, but collective bargaining has established a 40-hour week for most unionized workers in the formal economy across all sectors.

According to the national survey report, the working hours for different occupations: low/non-skilled sectors such as agriculture tend to work less than 40 hours per week, whereas higher skilled occupations such legislators/managers or clerks work for more than 40 hours per week. Close to $58 \%$ of security personal, $53 \%$ Plant \& machine operators, and $38 \%$ of service/sales workers worked more than 60 hours a week. To the contrary, $18 \%$ of the employed worked less than 20 hours in their main job. A little more than (55\%) of those employed had no written contract (Asenso-Okyere et al., 2000). These statistics provide enough grounds on why some sector is considered more important than others.

Ghana in the pre-recession era allows for men to enjoy various jobs than women; which means that there was prominent gender-based labour market segmentation that characterised the economy. Nonetheless, the overwhelming economic downturn culminating into rigid constraints of the formal market, compels most men to use food vending business as economic-survival-strategy by negotiating and competing with their female counterparts in the trade. Studies have shown that, this gender competition in food vending industry in Ghana has been a recent phenomenon, and consequently has not captured the attention of people (Shambos, 1999). Forkuor (2016: p. 94) alludes to the fact that lots of scholarly research have been done on the subject, but then, attention is focused on the condition under which bar (local restaurant) operators operate. Emphasis is placed on healthy environment so that these chop bars and food vending shops would not pose health risk to consumers. But the cultural ideals which are intertwined and implicated in the trade have not received much applause. Thus, "the focus of research has been predominantly on health issues and safety without much attention to the socio-cultural aspects of street vending" (Forkuor, 2016: p. 94). This paper, as part of its aims would unearth how socio-cultural tenets are played within the context food vending business in relation gender roles in Kumasi.

\section{Mode of Entering/Gaining Access into the Trade by Men}

Simpson (2004: p. 355) examines three (3) basic mode of entrance into food vending business by men. He describes the first as seekers; those who voluntarily choose this trade as source of livelihood. Men in this case see food vending as a normal job that ensures their livelihood. The second category he calls finders; those who accidentally find this trade in their search for a decent job. And finally, the settlers; denote those who forcefully take up this work as a result of hard economic depression. Whatever the drive may be, the trade is used as a safety valve to cope with the formal market constraints. What is revealing here is that the absence of welfare services or State generated jobs, means that the State is 
clearly aware of food vending as informal normative activity.

But what does it mean to a man to break through conventional barriers to engage in female-dominated business setting such as Kumasi? Empirical data establishes the fact that the male food vendor stand to gain upper hand in terms of earnings over their female counterparts Levin et al. (1999). For instance, Williams (1992: p. 263) calls these privileges "glass escalator" or the "glass escalator effect", and that the subculture formed by male food vendors in female-dominated trade springboard them to certain level of advantages over female vendors. Similarly, Floge \& Merrill (1986: p. 926) call this "heighten visibility", describing the tendency that their minority status makes them attractive to customers. They succinctly re-echo this conceptual framework in Forkuor's (2016: p. 95, emphasis added) study that; "the advantages that the [men as] minority groups might enjoy in [the female dominated food vending business] result from the fact that as a minority group, their actions are easily noticed or highly visible, creating the impression that they are working hard than others, which in reality may not be so". Conversely, they equally face social scorn and community indignity. This is because cooking which is seen as a symbol of femininity should not be engaged in by men as this reduces their masculine status.

Nonetheless, Maume (1999: pp. 489-490) finds out in his empirical studies into how race and gender could affect one's occupation, concludes that these privileges men enjoy in female dominated business, such as food vending are likely to be affected by ethnicity, race, religion and even geographical location of the vendor. This finds explanation in the type of food a vendor prepares; a customer may choose to buy a favourite local dish from a seller regardless of sex. Also, an ethnic and religious inclined customer will prefer buying food from vendor if he/she shares similar beliefs and practices with.

\section{Challenges Men Face in the Food Vending Industry in Kumasi}

According to Forkuor (2016: p. 95, emphasis mine), men also "suffer from what they called identity crises, a challenge to their masculinity and questioning of their sexuality... and also suffer from 'role strain' as they try to balance patriarchal values with the famine tricks of the trade". In the words of Zanden (1990), the individual may also suffer what he calls "role conflict", as in discharging duties as food vendor would undoubtedly violate his masculine ideals; providing for the family, security and role model. This is because this trade diffuses the male agenda as a father-figure who establishes discipline and seen as a role model in the family as most of his time is virtually spent outside the home. Again, the male food vendors in the eye of a patriarchal society like Kumasi face social stigma, emasculation and ridicule in the society. And this is confirmed by Forkuor (2016) that these men are scorned and mocked by society for engaging in a business purported to be women's. These societal reactions stem from the fact that cooking, traditionally, is meant for women, and so it is not only an insult to masculinity, but it is also an indictment to the patriarchal values. 
But as argued before, men in patriarchal society will choose to sacrifice anything to protect the values attached to masculinity when it is challenged. They do so by providing mechanisms to justify any action that seem to digress from the conventional practices. Therefore, men with the drive to maintain the status quo try to fulfil their patriarchal normative expectations at the same time doing their job (Cha \& Thébaud, 2009). They do so by making sure they provide for the family, ensure discipline and care for the family (Forkuor, 2016: p. 99).

It is important to add that men in this situation have developed defensive mechanisms to help normalise their involvement in the trade. They do so first; by reconsidering their statuses and roles in the business. For instance, most men who operate traditional catering system now assume positions as managers and supervisor, and hire women especially, migrants as workers. Another justification stems from the fact that the trade has constitutional approval as a socially acceptable source of livelihood in Ghana.

\section{Gender in Food Vending Business Verses Socio-Cultural Practices}

The belief systems of those who patronise food from food vendors have an inherent influence on their behavioural patterns in terms food consumption in the industry. For instance, Rheinländer et al. (2008: p. 959) study attests to the fact that, customers consider food hygiene practices of the vendor before a decision to patronise food; the physical surrounding and outfit of a vendor inform a customer's choice of menu from vendors. On the basis of this, female food vendors, especially the mothers, are likely to lose these aesthetic considerations because of postnatal child care related issues. Consequently, most customers in food vending business choose to buy food from male food vendors because men are considered to be clean and neat as opposed to female food vendors. This gendered interpretation of hygiene allows Scott (1986, p. 1068) to question customers' subjective explanation of cleanliness and neatness, by raising issues of subjectivity and ideology. What does it mean to be clean and neat? Who defines these terms? She finds the answers in the conventional practices and norms which perpetuate social-asymmetries between men and women in the society. Forkuor (2016, p. 98) study remarkable confirms that, in terms of cleanliness there is no difference between the working environment of most female food vendors and their male counterparts, but the subjective meaning attached to the various sexes vis-à-vis neatness, gives most male food vendors an upper hand. What the authors find ironic and hypocritical about this behavioural pattern of most customers is that most men in food vending business have female employees who virtually do the cooking and they (men) do the selling.

Another contributory factor that influences the choice of food vendor by a customer is the issue of trust. Rheinländer et al. (2008: p. 961) find two basic criteria that characterize a customers' faith in a vendor. First, is reputation and second; the relationship one develop with a food vendor. The former is won by vendor through respect, truthfulness and integrity either by direct or indirect 
experience of a customer. The latter, is through an individual's relationship with a vendor. The general perception that women are not trustworthy resonates in the customer relationship with female vendors. Most people will choose to satisfy their hunger in male catering services for personal safety and the trust they have in men over women (Rheinländer et al., 2008: p. 961).

Moreover, another ideological obstacle female food venders face, and that give their male counterparts advantage over them is their menstrual cycle. "Menstruation, which is an aspect of womanhood is... used to enhance the distinction between men and women and to increase the idea that women 'naturally are unclean' and therefore should allow men to take charge of the food vending business" (Forkuor, 2016: p. 98, emphasis added). In most traditional homes in Ghana, for example, traditional healers and medicine men alike will practically ban women from cooking during menstrual period. The belief is that she is ritually considered as an "unclean being", and therefore, likely to attract the wrath of the spirits behind the healing powers which detest "uncleanliness". Consequently, "these religiously found ideas about menstruation, added to the general perception of 'women as unclean' forcefully allow female food vendors to forcefully relinquish their traditional 'birth rights' as cooks to male food vendors" (Forkuor, 2016: p. 98, emphasis mine). The justification of this belief relies heavily on the gendered assumptions and religious norms that seek to give interpretation to masculinity and femininity in order to justify structural and symbolic inequalities (Scott, 1986: p. 1067). Kofi Agekum argues also that, customers who often use menstruation as a justification for shunning away from female food vendors fail to understand the fundamental importance of the phenomenon, and that this perceived assumption is only "used in male-dominated gender-asymmetrical society like the Akan—the people of Kumasi" (Agyekum, 2002: p. 384, emphasis is added).

\section{Gender-Labour Market Nexus; Implication on the Family and the State}

1) The Family.

In Ghana, the symbol of food/food vending is associated with female activity, the sole preserve for women. Therefore, men in the food vending business are seen as violation, at the same time a transgression of the conventional norm about the division of labour between men and women. Nonetheless, these changes within the labour market resonate with the fact that men are now ready to negotiate the long-standing tradition that the kitchen is the preserved of the woman. It implies also that gender roles are now changing and occupational segregation will become more blur. This according to Kornblum (as cited in Forkuor, 2016: p. 100) posits that; "the fact that these men are negotiating gender roles lends more evidence to the argument that gendered division of labour has never been fixed, [and that] gender roles have historically been adapted to suit new and emerging conditions".

Further, one could equally argue that more respect is now accorded to jobs 
which hitherto were considered as menial. It is also very important to assert that the position of the man as the primary breadwinner in this changing phase of events will become obsolete. Cynthia Enloe, in her contention on this gendered-asymmetric notion of men as breadwinners of the house, and therefore, a justification of the unequal power relations among actors in the labour market records that in most rural settings; fathers sometimes depend solely on the income their female migrants send home. And there come instances also where single parenting as a result of divorce, death and economic depression allow some women to assume the position as primary breadwinners in their respective families (Enloe, 2014: pp. 279-281). Therefore, this notion is baseless, and nothing more than a traditional patriarchal norm to discredit women in order to maintain male-domination.

2) The State.

The growing interest of men to break the conventional barriers to go into task which supposedly labelled as women should be considered as socio-cultural novelty in the art of food preparation and services in the nation Ghana. Therefore, credit facilities and loans should be made available to individuals who want to go into business that promote gender friendliness and balance in the country. State, in the context of neo-liberalism allows supply and demand forces to determine the success of food vendors, of both sexes. This reinforces gender stereotyping. Also, the State apparatus; the constitution, statutes and conventions which resonate with post-1957 independence ideas and practices connote Western way of life which may in way relatively embrace equality within the labour market. But in the pre-1957 independence era, the customs and traditions of the people ruled them. It is therefore not surprising that people pattern of behaviour is based on customs and traditions which inherently reflect their life within the labour market.

\section{Recommendations}

In Ghana, and for that matter sub-Saharan Africa, the belief that food and for that matter cooking is culturally recognised as a symbol of womanhood. Therefore, the society expects that food vending is women occupation. But the fact that economic implications and formal market constrains compel men to digress from in this conventional practice is an indication that men are now ready to negotiate and to question some of these long-standing traditions that downgrade other groups. From the argument, it is undoubtedly clear that the informal sector of the economy is a source livelihood to many and could possibly be a sector that promotes gender egalitarian ideology within the labour market in Ghana. However, the lack of pragmatic measures to ensure the protection of workers in the informal sector of the economy allows some unscrupulous state officials and individuals alike to exploit workers. Consequently, the trade union policies by the Ghana government to safeguard the interest of actors in the sector should be strengthened to guarantee the rights and liberties of individuals in the sector.

Again, the rigid bureaucratic processes of state apparatuses that make it un- 
easy for individuals to air their plight should be made flexible so that workers in the sector would be able to freely channel their grievances to the appropriate authorities for redress. Further, the State Ministries such as Trade and Industry and Employment and Labour Relations should intensify their efforts to respond appropriately to the needs of this sector of the economy so that sole proprietors in this business should register with the state to make their activities formal. This will guarantee their contribution towards the future, which will ease the state in welfare provision for people in the future. We concur with Haug (2014: p. 11) that, "the state should make accessible the services such as social security, healthcare, as well as credit and financial schemes" to workers in this sector. Thus, it behoves the state to provide friendly policies and interventions to make the sector accommodating for all. By doing so, it will go a long way to boosting the contribution of the informal sector of the economy for national development. Finally, we suggest that the State should put in place measures to confront the gender specific challenges within the labour market in Ghana.

\section{Conclusion}

In summary, this paper examines the clash of gender roles; masculinity verses femininity through food vending business in Kumasi, Ghana. It is established that, though culture could be hindrance in the choice of one's career, the individual stands to gain sometimes in gender role reversal. Also, the impact of culture in the food vending business which informed the behavioural patterns in customers' food consumption was dealt with succinctly. The constraints male vendors encounter, the implication of men engagement in food vending business in Kumasi vis-à-vis the family and the state were also given a fair attention. Finally, what the individuals or groups, civil society organisations need to do to improve this sector is recommended for the individual actors in the economy.

\section{References}

Aggleton, P., Boyce, P., Moore, H., \& Parker, R., Eds. (2016). Understanding Global Sexualities: New Frontiers. Milton Park: Routledge.

Agyekum, K. (2002). Menstruation as a Verbal Taboo among the Akan of Ghana. Journal of Anthropological Research, 58, 367-387. https://doi.org/10.1086/jar.58.3.3631182

Asenso-Okyere, W. K., Twum-Baah, K. A., Kasanga, A., Anum, J., \& Pörtner, C. (2000). Ghana Living Standards Survey. Report of the Fourth Round (GLSS 4). Accra, Ghana: Ghana Statistical Service.

Cha, Y., \& Thébaud, S. (2009). Labor Markets, Breadwinning, and Beliefs. How Economic Context Shapes Men's Gender Ideology. Gender \& Society, 23, 215-243. http://gas.sagepub.com/content/23/2/215.abstract https://doi.org/10.1177/0891243208330448

Enloe, C. (2014). Women's Labour Is Never Cheap. Gendering Global Blue Jeans and Bankers. In Bananas, Beaches and Bases: Making Feminist Sense of International Politics (pp. 250-304). Berkeley: University of California Press.

Floge, L., \& Merrill, D. M. (1986). Tokenism Reconsidered: Male Nurses and Female Physicians in a Hospital Setting. Social Forces, 64, 925-947. 
https://doi.org/10.1093/sf/64.4.925

Forkuor, J. B. (2016). Food Vending among Men in Kumasi: Socio-Cultural Advantages, Constraints, and Coping Strategies. International Journal of Social Science Studies, 4, 94-102. http://redfame.com/journal/index.php/ijsss/article/view/1278 https://doi.org/10.11114/ijsss.v4i2.1278

Ghana Statistical Service (2013). 2010 Population and Housing Census: National Analytical Report, 430.

http://www.waikato.ac.nz/_data/assets/pdf_file/0007/180592/Norway-2001-en.pdf

Haug, J. (2014). Critical Overview of the (Urban) Informal Economy in Ghana. Accra: Frieddrich Ebert Stiftung.

Levin, C. E., Ruel, M. T., Morris, S. S., Maxwell, D. G., Armar-Klemesu, M., \& Ahiadeke, C. (1999). Working Women in an Urban Setting: Traders, Vendors and Food Security in Accra. World Development, 27, 1977-1991. https://doi.org/10.1016/S0305-750X(99)00096-0

Maume Jr., D. J. (1999). Glass Ceilings and Glass Escalators: Occupational Segregation and Race and Sex Differences in Managerial Promotions. Work and Occupations, 26, 483-509. https://doi.org/10.1177/0730888499026004005

Rheinländer, T., Olsen, M., Bakang, J. A., Takyi, H., Konradsen, F., \& Samuelsen, H. (2008). Keeping up Appearances: Perceptions of Street Food Safety in Urban Kumasi, Ghana. Journal of Urban Health: Bulletin of the New York Academy of Medicine, 85, 952-964. https://doi.org/10.1007/s11524-008-9318-3

Scott, J. W. (1986). Gender: A Useful Category of Historical Analysis. American Historical Review, 91, 1053-1075. https://doi.org/10.2307/1864376

Shambos, S. (1999). Sustainable Development and International Economic Cooperation: Women in Development. Statement by the Representative of Cyprus to the UN 2nd Committee. http://www.kypros.org/UN/salina.htm

Simpson, R. (2004). Masculinity at Work: The Experiences of Men in Female Dominated Occupations. Work, Employment \& Society, 18, 349-368. https://doi.org/10.1177/09500172004042773

Williams, C. L. (1992). The Glass Escalator: Hidden Advantages for Men in the "Female" Professions. Social Problems, 39, 253-267. https://doi.org/10.2307/3096961

Zanden, V. J. W. (1990). Sociology' The Core. New York: McGraw Hill Publishing Company. 